\title{
ПРАКТИЧЕСКОЕ ПРИМЕНЕНИЕ ПРЕДИКТИВНОЙ ДИАГНОСТИКИ САХАРНОГО ДИАБЕТА 2 ТИПА У ЛИЦ ПОЖИЛОГО ВОЗРАСТА
}

\author{
${ }^{1}$ Безродный С.Л., ${ }^{1}$ Затевалов А.М., ${ }^{2}$ Терешина Е.В.
}

'ФГБУ «Московский научно-исследовательский институт эпидемиологии и микробиологии имени Г.Н. Габричевского» Роспотребнадзора, Москва

2«Российский национальный исследовательский медицинский университет имени Н.И. Пирогова», Москва

ЦЕЛЬ: определить маркеры сахарного диабета (СД) 2 типа у лиц пожилого возраста предиктивным анализом концентраций малых молекул (ММ) в крови.

МАТЕРИАЛЫ И МЕТОДЫ: в обсервационном исследовании образцов крови, полученных от 163 пациентов амбулаторного приема НКЦ геронтологии в возрасте 45-90 лет, определили концентрации ММ в крови. На основании клинико-анамнестических данных и результатов лабораторных исследований врачом-эндокринологом, пациентам устанавливали диагноз СД 2 типа. Из пациентов С диагнозом СД 2 типа была сформирована группа СД 2 типа - 103 пациента, а пациенты без этого диагноза составили группу сравнения (ГС) - 60 пациентов. Группы сопоставимы по возрасту. Гендерные различия не учитывались.

Для определения концентраций ММ в крови использовали метод газовой хроматографии массспектрометрии с преаналитической подготовкой проб в соответствии с МУ 4.2.2039-05 пункт 3 и учебнометодическому пособию «Методика масс-спектрометрии микробных маркеров как способ оценки пристеночной кишечной микробиоты при заболеваниях органов пищеварения», под редакцией Г.А. Осипова, В.П. Новиковой, Санкт-Петербург - 2013 г.

Для расчета формулы диагностических коэффициентов СД 2 типа использовали линейный дискриминантный канонический анализ (ЛДА), анализ сопряженности с прямой пошаговой процедурой включения показателей концентраций микробных маркеров в крови (Statistica 10.0 StatSoft, США).

РЕЗУЛЬТАТЫ: при проведении ЛДА были включены показатели концентраций: 3-гидроксимиристиновой (3h14), 10-метилпальмитиновой (10Mе16), изононадециловой (i19), 9-изогептадеценовой (i17:1 d9); транс-9-гексадеценовой (16:1 d9t), 2-гидрокситетракозановой (2h24) кислот, холестендиола в крови. На основе включенных компонентов относительных концентраций ММ микробного происхождения в крови была рассчитана математическая модель с условным названием «Сахарный диабет». Значение Лямбда Уилкса составило 0,59036, $\mathrm{p}<0,0001$. Наименьшее значение частной лямбды Уилкса отмечается для изононадекановой (i19) кислоты (0,896751), что указывает на наибольший вклад этого показателя в дискриминацию исследуемых групп.

Математическая модель «Сахарный диабет» имеет 85,88\% прогностической точности (таблица 2), при 80,35\% специфичности и 88,78\% чувствительности, что является высокими прогностическими показателями.

\section{выводы:}

1. Специфическое состояние микробиома человека при СД 2 типа у лиц пожилого возраста может быть выявлено с помощью расчета концентраций ММ в крови пациентов по диагностическим коэффициентам ЛДА.

2. Решающие правила математической модели «Сахарный диабет», характеризуются следующими показателями качества классификации: прогностическая точность - 85,88\%; специфичность - 80,35\%; чувствительность - $88,78 \%$.

КЛЮЧЕВЫЕ СЛОВА: микробные маркеры; предиктивная диагностика СД2; дискриминантный анализ; изононадециловая кислота. 